\title{
ResCOVID: aprendizados e adversidades sob a ótica multiprofissional na pesquisa com prontuários médicos
}

\author{
ResCOVID: learning and adversities under multiprofessional optics in research with medical \\ records
}

ResCOVID: aprendizaje y adversidad desde una perspectiva multidisciplinar en la investigación con historias clínicas

André Ribeiro de Castro Júnior ORCID: https://orcid.org/0000-0002-3681-3607 Escola de Saúde Pública do Ceará, Brasil E-mail: andrecastrorcj@gmail.com

Maria Iara Socorro Martins ORCID: https://orcid.org/0000-0001-9366-8621 Escola de Saúde Pública do Ceará, Brasil E-mail: iara.martins16@gmail.com

Marcos Augusto de Paula Santos ORCID: https://orcid.org/0000-0003-3632-3904 Escola de Saúde Pública do Ceará, Brasil

E-mail: marcosaugustodepaula@outlook.com

Ana Naiara Alves Teixeira

ORCID: https://orcid.org/0000-0002-4069-0515 Escola de Saúde Pública do Ceará, Brasil E-mail: ananaiaraat@gmail.com

Thalyta Gleyane Silva de Carvalho ORCID: https://orcid.org/0000-0003-1728-4719 Universidade Federal do Ceará, Brasil

E-mail: thalytagleyane@gmail.com

Daniel Germano Alcântara

ORCID: https://orcid.org/0000-0002-0798-6293 Escola de Saúde Pública do Ceará, Brasil E-mail: dgermano25@hotmail.com

Camila Campos Colares das Dores ORCID: https://orcid.org/0000-0002-2619-665X Escola de Saúde Pública do Ceará, Brasil

E-mail: camilacamposcolares@gmail.com

Francisco Aislan da Silva Freitas ORCID: https://orcid.org/0000-0002-0949-1876 Escola de Saúde Pública do Ceará, Brasil E-mail: aislansf@gmail.com Ana Paula Matos Porto ORCID: https://orcid.org/0000-0003-3641-9746 Universidade de São Paulo, Brasil E-mail: aporto@usp.br

Francisco Jadson Franco Moreira ORCID: https://orcid.org/0000-0003-3141-4700 Universidade Estadual do Ceará, Brasil E-mail: jadsonpsic@hotmail.com

\begin{abstract}
Resumo
Objetivo: Narrar a experiência multiprofissional na pesquisa em prontuário médico junto à plataforma ResCOVID. Metodologia: Trata-se de uma pesquisa descritiva com abordagem qualitativa, do tipo relato de experiência, realizada em um hospital da rede pública de saúde da cidade de Fortaleza-Ceará. A vivência relatada ocorreu durante o período de maio de 2020 à abril de 2021 em uma coleta de dados retrospectiva feita através de uma equipe multiprofissional no projeto intitulado "Um sistema de registro clínico eletrônico para pacientes hospitalizados com COVID-19 em um hospital de referência no Ceará - ResCOVID”. Resultados: As experiências vivenciadas pelos pesquisadores destacam como principais dificuldades encontradas no processo de coleta de dados, a carência de dados, a inconsistência dos dados, os pacientes sem teste diagnóstico para COVID-19, o modo de coleta, o instrumento de coleta e o medo de aquisição da infecção pelo local de pesquisa. Considerações Finais: Os resultados encontrados através da experiência
\end{abstract}


relatada nesse estudo reforçam a importância na busca constante do desenvolvimento de inovações e melhorias recursos para se fazer pesquisa, que contribuem positivamente no processo de investigação, e que mesmo diante das limitações estruturais encontradas, avanços são obtidos e vem contribuindo, trazendo agilidade e confiabilidade no escopo da coleta.

Palavras-chave: COVID-19; Prontuário médico; Tecnologias em saúde; Equipe multiprofissional.

\begin{abstract}
Objective: Narrate the multiprofessional experience in research using medical records to insert the data in the RESCOVID platform. Methodology: This is a descriptive research with a qualitative approach of the type of experience report, carried out in a public health hospital in the city of Fortaleza-Ceará. The reported experience occurred during the period from May 2020 to April 2021 in a prospective collection performed by a multiprofessional team participating in the project entitled "An electronic medical record system for patients hospitalized with COVID-19 in a reference hospital in Ceará - ResCOVID ". Results and discussion: The experiences lived by the collectors highlight main difficulties found in the data collection such as of data, inconsistency of data, patients without a diagnostic test for COVID-19, data collection method and fear of infection due to the research site. Final considerations: The results found through the experience reported in this study reinforce the importance of the constant search for the development of innovations and improvements in the resources to do research, in the resources to do research. In addition, even in face of structural limitations, these advances in the investigation process may bring agility and reliability to the scope of data collection.

Keywords: COVID-19; Medial record; Health technologies; Multiprofessional team.
\end{abstract}

\title{
Resumen
}

Objetivo: Narrar la experiencia multidisciplinar en la investigación de historias clínicas con la plataforma ResCOVID. Metodología: Se trata de una investigación descriptiva con enfoque cualitativo, del tipo informe de experiencia, realizada en un hospital de salud pública de la ciudad de Fortaleza-Ceará. La experiencia relatada ocurrió durante el período de mayo de 2020 a abril de 2021 en una recolección de datos retrospectiva realizada por un equipo multidisciplinario en el proyecto titulado "Un sistema de historia clínica electrónica para pacientes hospitalizados con COVID-19 en un hospital de referencia en el Ceará - ResCOVID ". Resultados y discusíon: Las experiencias vividas por los investigadores destacan como las principales dificultades encontradas en el proceso de recolección de datos, la falta de datos, la inconsistencia de los datos, los pacientes sin una prueba diagnóstica para COVID-19, el método de recolección, el instrumento de recolección y el miedo. de adquisición de la infección por el sitio de investigación. Consideraciones finales: Los resultados encontrados a través de la experiencia reportada en este estudio refuerzan la importancia en la búsqueda constante por el desarrollo de innovaciones y mejoras en los recursos para la investigación, que contribuyan positivamente al proceso de investigación, y que incluso frente a limitaciones estructurales encontrado, se obtienen avances y se ha ido contribuyendo, aportando agilidad y confiabilidad al alcance de la cobranza.

Palabras clave: COVID-19; Historia clínica; Tecnologías sanitarias; Equipo multiprofesional.

\section{Introdução}

Com o aparecimento e rápida propagação do novo Coronavírus, muitos desafios foram impostos para as instituições de saúde públicas e privadas em todo o mundo, a demanda de recursos físicos, materiais e profissionais exigiu do setor saúde ações rápidas para diminuir o avanço dessa pandemia ocasionada pelo novo Coronavírus SARS-CoV-2 (Chu et al., 2020; De Felice, et al., 2020).

A dificuldade com a nova doença não advém apenas da demanda de recursos financeiros, mas também da carência de novos conhecimentos sobre formas de transmissão, sintomas, tratamento e possíveis desfechos. A inexistência de um tratamento específico, o avanço insuficiente da cobertura vacinal e as mutações virais têm desafiado pesquisadores e gestores em saúde no alcance de medidas que diminuam o risco da expansão da doença e o colapso dos sistemas de saúde (Aquino, et al., 2020).

Seja para fins de conhecimento sobre o perfil de pacientes, comportamento de doenças e previsão de desfechos, a pesquisa em prontuários médicos surge como uma opção viável a pesquisadores na procura por atender as lacunas do conhecimento. O prontuário do paciente acomoda o registro assistencial, ético-legal e científico do processo saúde-doença do cliente e seu respectivo tratamento, permitindo controle e continuidade das medidas terapêuticas aplicadas (De Souza, et al., 2020).

O prontuário permite uma análise quantitativa para a geração de indicadores relacionados a questões de conhecimento sobre a doença, a assistência e até a gestão, possibilitando ainda traçar a tomada de decisões administrativas e assistenciais. 
Contudo, os prontuários manuscritos e eletrônicos ainda apresentam fragilidades em seu preenchimento e clareza nas informações, podendo em alguns casos diminuir a confiabilidade das informações (Ribeiro, et al., 2018; Barbosa, et al., 2020).

Neste trabalho é tecida a discussão sobre a coleta de dados em prontuários eletrônicos, assim como suas contribuições e desafios. Cabe ainda, na oportunidade, a apresentação da Plataforma ResCOVID como instrumento de coleta da pesquisa e sua potencialidade narrada pelos coletores da pesquisa. Trazemos como objetivo narrar a experiência multiprofissional na pesquisa em prontuário junto a plataforma ResCOVID.

\section{Metodologia}

Trata-se de uma pesquisa descritiva com abordagem qualitativa, do tipo relato de experiência, realizada em um hospital da rede pública de saúde, referência no tratamento da COVID-19 situado na Cidade de Fortaleza (Ceará). Os métodos qualitativos descrevem a interpretação do pesquisador sobre o fenômeno em estudo, com base em vivências e experimentações (Pereira, et al., 2018).

A vivência descrita aqui narra a oportunidade de uma equipe multiprofissional ao participar do projeto piloto intitulado "Um sistema de registro clínico eletrônico para pacientes hospitalizados com COVID-19 em um hospital de referência no Ceará ResCOVID". O projeto é desenvolvido pela Escola de Saúde Pública do Estado do Ceará - ESP, junto à Secretaria de Saúde do Estado do Ceará - SESA, e consiste no desenvolvimento e validação de uma plataforma eletrônica para registro de informações de pacientes acometidos pela COVID-19.

A coleta de informações sobre pacientes em prontuário e que se divide em dois momentos distintos. Na primeira fase (maio a outubro de 2020), os coletores/pesquisadores utilizaram como ferramenta para a coleta de dados do paciente, um documento da plataforma digital do Google Forms, categorizado em sessões com perguntas fechadas e abertas.

No segundo momento, a plataforma ResCOVID entra em funcionamento como substitutiva para o formulário do Google Forms, comportando os dados da pesquisa, permitindo o preenchimento e organização dos dados de uma forma mais ágil, eficiente e segura.

Para cada coletor foi designado um dia de referência para coleta. Todos os pacientes internados neste dia foram designados a um coletor específico que realizou a consulta ao censo de pacientes, a busca por informações em prontuário e o preenchimento dos campos importantes para a pesquisa. O modelo a seguir descreve a trajetória da coleta por meio dos coletores neste projeto. 
Figura 1: Fluxograma Coleta de Informações, Fortaleza-CE, 2021.

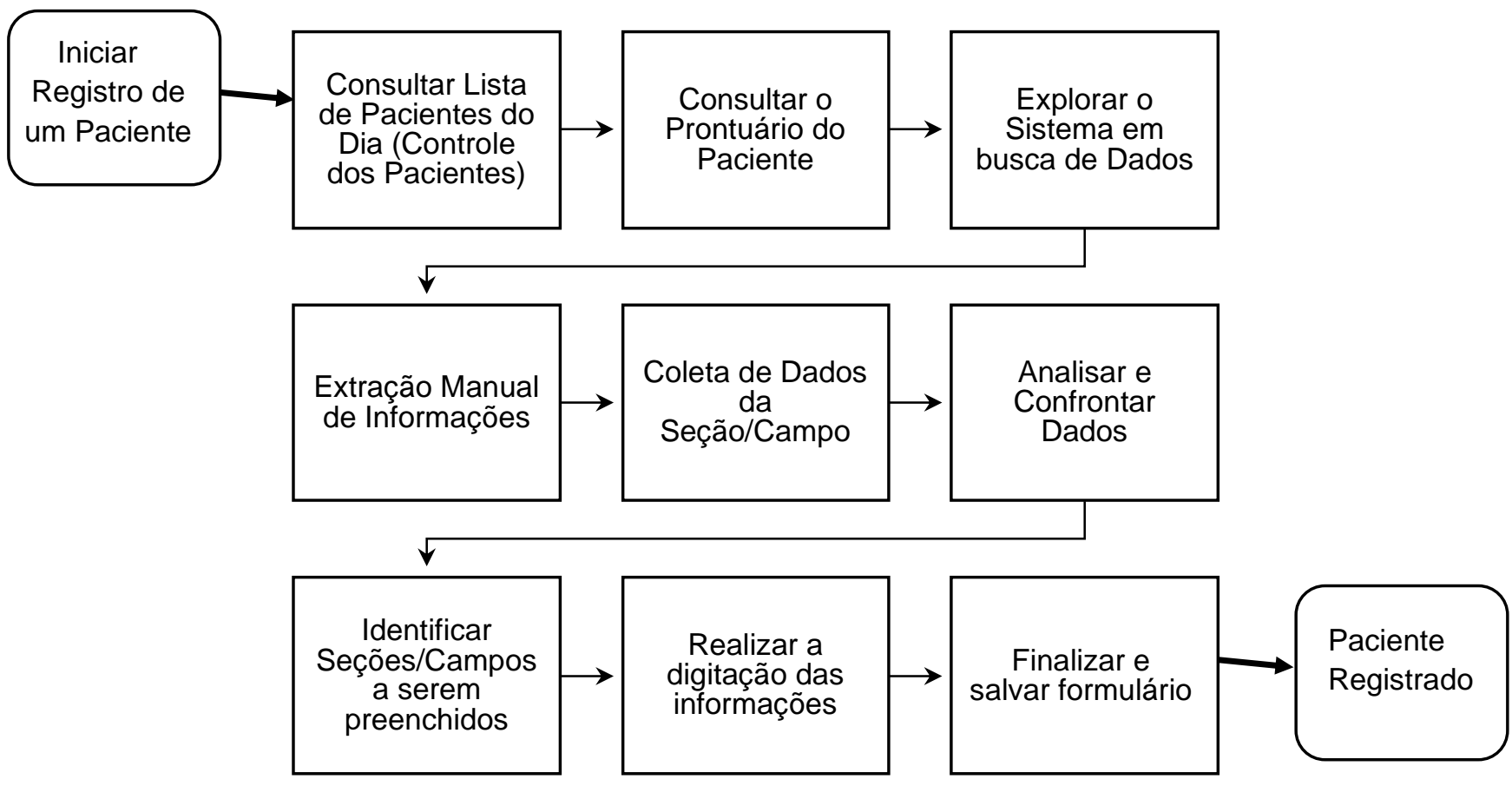

Fonte: Autores.

Por contar com um processo de várias etapas, a coleta de informações demanda do sistema ResCOVID alterações e melhorias sugeridas pela equipe de pesquisa na busca de seu aperfeiçoamento para fins de coleta de dados. A experiência descrita relata a vivência dos coletores durante o período de maio de 2020 a maio de 2021, apresentando o número de 2262 pacientes/prontuários incluídos neste período em uma coleta retrospectiva relatada sob ótica dos coletores.

As informações abordadas traduzem a rotina vivenciada presencialmente por quem interagiu diretamente em um local marcado pelas inseguranças trazidas pela nova pandemia, emergindo de relatos e observações em meio ao trabalho que produzirá fontes de materiais, estudos e discussões sobre o que representa o cenário enfrentado.

\section{Resultados e Discussão}

Durante o processo de implementação da pesquisa no hospital de referência pode-se observar, com base nas experiências vivenciadas, algumas características inerentes deste processo de coleta, a saber, 1) carência de dados, 2) inconsistência dos dados, 3) pacientes sem teste diagnóstico para COVID-19, 4) migração do modo de coleta, 5) instrumento de coleta e 6) medo de infecção devido o local de pesquisa, as quais estão melhor descritas no Quadro 1. 
Quadro 1: Síntese das dificuldades encontradas durante o período da coleta, Fortaleza-CE, 2021.

\begin{tabular}{|c|c|}
\hline DIFICULDADES PARA A COLETA & DEFINIÇÕES \\
\hline 1) Carência de dados & $\begin{array}{l}\text {-Incompletude e falta de padronização no preenchimento de dados por } \\
\text { profissionais da instituição }\end{array}$ \\
\hline 2) Inconsistência dos dados & $\begin{array}{l}\text {-Informações incorretas, valores com erros de digitação } \\
\text {-Utilização de siglas aleatórias e sem reconhecimento científico } \\
\text {-Dados apresentando repetições }\end{array}$ \\
\hline $\begin{array}{l}\text { 3) Pacientes sem teste diagnóstico para } \\
\text { COVID-19 }\end{array}$ & $\begin{array}{l}\text {-Falta de informações em prontuário sobre informações de RT-PCR ou } \\
\text { outro teste diagnóstico }\end{array}$ \\
\hline $\begin{array}{l}\text { 4) Migração do modo de coleta (Google } \\
\text { Forms para a plataforma ResCOVID) }\end{array}$ & $\begin{array}{l}\text {-Impossibilidade de salvamento parcial no Google Forms e perda das } \\
\text { informações } \\
\text {-Impossibilidade de visualização ou correção dos dados já cadastrados } \\
\text { pelos coletadores } \\
\text {-Adequação a um novo sistema }\end{array}$ \\
\hline 5) Instrumento de coleta & $\begin{array}{l}\text {-Seguidas alterações nos dados a serem coletados conforme demandas do } \\
\text { objetivo do estudo piloto e ampliação para outros hospitais } \\
\text {-Necessidade do uso de planilhas }\end{array}$ \\
\hline $\begin{array}{l}\text { 6) Medo de infecção pelo local da } \\
\text { pesquisa }\end{array}$ & $\begin{array}{l}\text {-Exposição a ambiente propício à contaminação } \\
\text {-Desconhecimento, sobretudo no início, sobre a doença } \\
\text {-Distanciamento de amigos e familiares }\end{array}$ \\
\hline
\end{tabular}

Fonte: Autores.

\section{Carência de Dados}

Um dos maiores desafios encontrados durante a coleta de dados foi a falta do registro de informações fundamentais para a pesquisa, tais como sinais vitais diários, resultados de exames, anotação do exame físico, assim como descrição clara e objetiva das complicações e causas do óbito.

Compreende-se que a carência do registro, muitas vezes é justificada pela sobrecarga de trabalho, o desconhecimento dos riscos da falta dessas informações, e até mesmo saber que o prontuário é um método de mensurar seus cuidados, um documento legal que respalda o profissional da saúde (Silva, et al., 2017).

Com base na vivência denota-se a importância de implementação de estratégias para elaboração de evoluções padronizadas, protocolos de cuidados informatizados contribuem para apontamentos consistentes e de qualidade, com o intuito de minimizar a falha de informações visando melhoria da qualidade da assistência e das anotações multiprofissionais (Carneiro, et al.,2016).

\section{Inconsistência dos Dados}

Os principais desafios encontrados nas consultas em prontuários eletrônicos foram as incoerências sobre a condição clínica dos pacientes, erros na digitação, incompletude de informações, valores incongruentes nos parâmetros de sinais vitais ou nos exames. Percebemos ainda informações conflitantes entre evoluções no mesmo dia, informando parâmetros destoantes ou incompatíveis com a situação clínica do paciente.

Notamos também como inconsistência, o uso intensificado de abreviaturas não padronizadas e aleatórias, o que demonstrou falta de clareza no registro da informação Tal achado é corroborado por Gomes et al. (2016), cujo estudo afirma que 
uma das falhas mais comuns cometidas pelos trabalhadores da saúde consiste no uso de abreviaturas desatualizadas que dificultam a compreensão dos registros.

Estudos apontam a necessidade de treinamentos e monitoramento por categoria profissional de aperfeiçoar as anotações realizadas pela equipe (Silva, et al., 2017; Pinto 2019). Os desafios durante a coleta sinalizam a necessidade da qualidade dos registros de dados representa um mecanismo de comunicação efetiva, para tanto, depende da padronização das evoluções nas instituições de saúde, devendo ser redigidos de forma precisa, objetiva e completa.

\section{Paciente sem teste Diagnóstico}

Durante a rotina de coleta, um achado recorrente foi a falta de registro do teste confirmatório para o diagnóstico da COVID-19, sobretudo no início do estudo, dificultando o registro de informações destes pacientes e gerando falhas no preenchimento dos formulários.

A partir da segunda onda, considerando o período de coletas com pacientes com data de internação a partir de 2021, observou-se uma mudança nesse perfil, sendo percebida com maior frequência os testes recomendados para o diagnóstico de COVID-19 (teste rápido de antígeno e/ou RT-PCR), realizados nas unidades de saúde públicas que referenciaram o paciente assim como em laboratórios ou farmácias privadas anteriores à internação hospitalar.

A subnotificação da COVID-19 também pode ser resultado do alto custo do RT-PCR, erros laboratoriais, acurácia do teste e carga viral no momento do exame (Iser, et al., 2020; Oliveira, et al., 2020).

A implementação diagnóstica baseada na realização de exames laboratoriais auxilia no uso racional das tecnologias em saúde, bem como no manejo clínico e monitoramento adequado dos casos, haja vista que os casos notificados mesmo que suspeitos acabam requerendo a adoção de protocolos de segurança específicos, gerando maior custo para a saúde e maior demanda dos profissionais assistenciais (Oliveira, 2020; Moreira, 2021; Escosteguy, et al., 2020) .

Essa experiência com a falta de informações sobre testes confirmatórios gera lacunas no conhecimento a respeito da real situação sobre indicadores de incidência da doença, representando desafios para a pesquisa em prontuário.

\section{Modo de Coleta}

O avanço rápido da doença e o aumento das lacunas de conhecimento determinou que o início da pesquisa fosse rápido e sua estruturação permitisse rápidas respostas. Com isso, utilizando-se dos prontuários eletrônicos, a ferramenta inicialmente utilizada para a coleta foi o Google Forms.

O Google Forms é uma plataforma disponível para a elaboração de formulários personalizados, simples e estruturados conforme necessidade de resposta às perguntas utilizadas. Porém durante o uso dessa plataforma, os pesquisadores enfrentaram algumas dificuldades, tais como: perda de informações devido à impossibilidade de salvamento parcial dos dados, distribuição das informações por categorias com limitações no registro conforme a ordem dos achados no prontuário, além da incapacidade de visualização prévia ou edição de dados coletados (Martins, 2019).

Algumas destas dificuldades foram sanadas pelo uso de uma plataforma exclusiva para coleta, o ResCOVID, o que, após o período de adequação ao novo ambiente digital, possibilitou maior agilidade na coleta e menor inconsistência ou redundância de informações. A implantação desta plataforma trouxe a funcionalidade do salvamento parcial das informações, visualização de campos já preenchidos e abertura de campos independentes no preenchimento, agilizando o processo de coleta em virtude da agilidade para o coletor de dados.

A plataforma ainda passa por melhorias e validações que permitirão melhor manuseio e maior agilidade na coleta. Atualmente a desvantagem percebida ainda se apresenta na impossibilidade de edição dos dados após o salvamento pelos coletores, gerando demandas para a equipe da Tecnologia da Informação componente do projeto. 


\section{Instrumento de Coleta}

A estruturação do instrumento de coleta dos dados foi organizada conforme estas questões globais investigativas passível de alterações ao longo da pesquisa pela definição inicial de escolha da instituição participante para a realização de um estudo piloto.

A substituição da coleta no Google Forms pela plataforma ResCOVID emerge em torno desta demanda de readequação das informações solicitadas e, sobretudo, por agilidade na coleta. Contudo, ainda com a plataforma melhorada persistem algumas limitações necessidades de melhoria a serem implementadas

A demanda de informações sobre parâmetros de exames laboratoriais (enzimas hepática, gasometria arterial, entre outros) e uso de equipamentos de aplicação de pressões positivas (ELMO), expuseram a inevitabilidade de uma mudança no percurso de armazenamento das informações, considerando a não existência de campos específicos para essa adequação, sendo necessário utilizar-se de planilhas online no formato Microsoft Excel.

Colaborando com a experiência, Souza (2020), demonstram que existem inúmeras dificuldades relacionadas a uma pesquisa, e a fase inicial se torna a mais desafiadora pela imaturidade de como os dados serão armazenados e quais objetos serão coletados. Diante disso, coleta de dados se torna uma das etapas mais importantes da pesquisa.

A construção do instrumento de pesquisa reflete a qualidade do processo metodológico e importância da interdisciplinaridade para melhor percepção e compreensão do objeto de estudo. O processo de construção da investigação é mutável pelos pesquisadores em consonância às necessidades emergentes e características observadas no contexto de pesquisa (Furtado, et al., 2020).

A experiência nas duas plataformas de coleta permite o avanço sobre o processo de coleta e armazenamento dos dados. Embora ainda não finalizada, a nova plataforma apresenta-se como potencial modelo no auxílio de coletas em pesquisas futuras.

\section{Medo de Infecção pelo Local da Pesquisa}

Em meio a uma situação epidemiológica de crescente aumento no número de casos da doença complicações e possíveis desfechos incompatíveis com a vida, tornou-se evidente a necessidade da pesquisa tanto numa esfera científica como social. Ao longo da pesquisa, um desafio enfrentado foi o sentimento de medo de aquisição da infecção pelos pesquisadores, devido ao local do estudo, um hospital de referência no estado para tratamento de pacientes com COVID-19.

Embora a pesquisa dados para a pesquisa se fizesse na forma digital, através dos prontuários eletrônicos, o contato com o ambiente, as pessoas e até pacientes muitas vezes era inevitável. Considerando Medeiros EAS (2020), a SARS-CoV-2 se transmite em ambientes fechados com pouca ventilação. Em hospitais onde se encontram um grande número de pacientes infectados existe um aumento do risco de contaminação.

O medo de contágio e aquisição da COVID-19 tem afetado todos os indivíduos, e essa insegurança tem alcançado todos os aspectos da vida, da visão individual à coletiva, provocando diariamente remodelações nas relações interpessoais, as quais se estendem também ao campo da pesquisa científica e requerem o estabelecimento de novos fluxos para a construção do conhecimento (Faro, et al., 2020; Medeiros, 2020).

Este medo descrito pelas pesquisas incorporadas nas vivências cotidianas e em outros contextos sociais nos permite visualizar a relação entre a pandemia e a vulnerabilidade sentida tanto em seus aspectos mais objetivos, quanto subjetivos (Furtado, et al., 2020).

Diante de toda a experiência relatada, podemos conferir que a Pesquisa no cenário de pandemia enfrenta muitos desafios, e estar disposto a elaborar estratégias para conseguir avançar mesmo diante dos desafios impostos se faz necessário. Devemos inda ressaltar que a inovação conseguida diante da implementação da plataforma ResCOVID vem contribuindo para esse avanço, trazendo agilidade e confiabilidade na metodologia de coleta. 


\section{Considerações Finais}

Desempenhar pesquisa neste momento pandêmico reforça a necessidade iminente de investigar e mais ainda de responder demandas na tentativa de compreender melhor os aspectos clínicos a curto e longo prazo, prognósticos e possíveis consequências desta doença.

Foi possível observar que as limitações apresentadas perpassam problemas já encontrados por outras pesquisas (ausência e inconsistências dos dados) e especificidades inerentes do manejo de uma nova doença (dificuldades na testagem, modo/instrumento de coleta e medo de aquisição de uma infecção), mas que não diminuem a importância da pesquisa em suas dimensões clínicas, científicas e sociais. Esse estudo reflete o desenvolvimento de uma pesquisa, com promissora resposta de lacunas do conhecimento e assim direcionamento na tomada de decisões da gestão e no campo da assistência em saúde.

\section{Referências}

Aquino, E. M., Silveira, I. H., Pescarini, J. M., Aquino, R., Souza-Filho, J. A. D., Rocha, A. D. S., \& Lima, R. T. D. R. S. (2020). Medidas de distanciamento social no controle da pandemia de COVID-19: potenciais impactos e desafios no Brasil. Ciência \& Saúde Coletiva, 25(1), $2423-2446$.

Barbosa, K. H., de Oliveira, L. C., da Costa, E. D., Hosoume, L. Z., Yagi, M. C. N., de Almeida Baricati, C. C., \& Karino, M. E. (2020). O uso do prontuário eletrônico como ferramenta no exercício da Enfermagem: relato de experiência.Brazilian Journal of Health Review, 3(6), $15803-15811$.

Carneiro, S. M., Dutra, H. S., da Costa, F. M., Mendes, S. E., \& Arreguy-Sena, C. (2016). Uso de abreviaturas nos registros de enfermagem em um hospital de ensino.Rev Rene, $17(2), 208-216$.

Souza, L. P., \& de Souza, A. G. (2020). Brazilian nursing against the new Coronavirus: who will take care for those who care?.Journal of Nursing and Health,10(4).

Chu, H., Chan, J. F. W., Yuen, T. T. T., Shuai, H., Yuan, S., Wang, Y., \& Yuen, K. Y. (2020). Comparative tropism, replication kinetics, and cell damage profiling of SARS-CoV-2 and SARS-CoV with implications for clinical manifestations, transmissibility, and laboratory studies of COVID-19: an observational study.The Lancet Microbe, 1(1), e14-e23.

De Souza, L. D. R., Volles, G. A., \& Ribeiro, M. (2020). O prontuário do paciente na área médica: direito ao sígilo versus interesse público sanitário na pandemia da COVID-19.Revista Pensamento Jurídico,14(2), 1-21.

De Felice, FG, Tovar-Moll, F., Moll, J., Munoz, DP, \& Ferreira, ST (2020). Síndrome respiratória aguda grave coronavírus 2 (SARS-CoV-2) e o sistema nervoso central.Trends in neurosciences, 43, (6), 355-357.

Escosteguy, C. C., Eleuterio, T. D. A., Pereira, A. G. L., Marques, M. R. V. E., Brandão, A. D., \& Batista, J. P. M. (2020). COVID-19: estudo seccional de casos suspeitos internados em um hospital federal do Rio de Janeiro e fatores associados ao óbito hospitalar. Epidemiologia e Serviços de Saúde, 30 , e2020750.

Faro, A., Bahiano, M. D. A., Nakano, T. D. C., Reis, C., Silva, B. F. P. D., \& Vitti, L. S. (2020). COVID-19 e saúde mental: a emergência do cuidado. Estudos de Psicologia (Campinas), 37,1, 1-14.

Furtado, L. A. C., Fegadolli, C., Chioro, A., Nakano, A. K., da Silva, C. G., de Paula, L., \& Nasser, M. A. Caminhos metodológicos de pesquisa participativa que analisa vivências na pandemia de Covid-19 em populações vulneráveis Revista Saúde em debate. 2020;44(4):306-318.

Gomes, D. C., Cubas, M. R., Pleis, L. E., Shmeil, M. A. H., \& Peluci, A. P. V. D. (2016). Termos utilizados por enfermeiros em registros de evolução do paciente. Revista Gaúcha de Enfermagem, 37(sup1), 1-8.

Iser, B. P. M., Sliva, I., Raymundo, V. T., Poleto, M. B., Schuelter-Trevisol, F., \& Bobinski, F. (2020). Definição de caso suspeito da COVID-19: uma revisão narrativa dos sinais e sintomas mais frequentes entre os casos confirmados. Epidemiologia e Serviços de Saúde, 29 , (3), e2020233.

Medeiros, E. A. S. (2020). A luta dos profissionais de saúde no enfrentamento da COVID-19. Acta Paulista de Enfermagem, 33 (1), 1-4.

Moreira, R. D. S. (2021). Análises de classes latentes dos sintomas relacionados à COVID-19 no Brasil: resultados da PNAD-COVID19. Cadernos de Saúde Pública, 37, (supl 1), e00238420.

Martins, L., Sartor, G. D., \& da Silva, M. P. (2019). Prontuário Eletrônico do Paciente: Adoção de novas tecnologias de acesso.Journal of Health Informatics,11(3), $67-73$.

Oliveira, E. S., Matos, M. F., \& de Morais, A. C. L. N. (2020). Perspectiva de resultados falso-negativos no teste de RT-PCR quando realizado tardiamente para o diagnóstico de covid-19.InterAmerican Journal of Medicine and Health, 3 (supl 1) 1-7.

Oliveira, T. M., \& Araújo, A. C. O. (2020). Consequências da subnotificação dos casos de COVID-19 para a saúde pública no Brasil.InterAmerican Journal of Medicine and Health, 3 (supl 1), e202003062.

Pereira A. S. et al. (2018). Metodologia da pesquisa científica. UFSM. 5.3) Koche, J. C. (2011). Fundamentos de metodologia cientifica. Vozes.

Pinto, L. F., \& Santos, L. J. D. (2020). Prontuários eletrônicos na Atenção Primária: gestão de cadastros duplicados e contribuição para estudos epidemiológicos.Ciência \& Saúde Coletiva, 4(25), 1305-1312. 
Research, Society and Development, v. 10, n. 8, e50910817658, 2021

(CC BY 4.0) | ISSN 2525-3409 | DOI: http://dx.doi.org/10.33448/rsd-v10i8.17658

Ribeiro, W. A., Andrade, M., Frash, D. M., Santana, P. P. C., Souza, D. M., \& Almeida, V. L. (2018). Implementação do prontuário eletrônico do paciente: um estudo bibliográfico das vantagens e desvantagens para o serviço de saúde. Revista Pró-UniverSUS, 9(1), 07-11.

Silva, L., Prado, M. A., Barbosa, M. A., Ribeiro, D., Lima, F., Andrade, L. Z., \& Silva, A. (2017). Inconformidades acerca dos registros em prontuários: percepção dos trabalhadores de saúde da região central do Brasil. CIAIQ 2017,2, 1570-1577. 